\title{
Identidades femeninas en el contexto profesional "masculinizado" de la ingeniería civil en el suroccidente colombiano ${ }^{1}$
}

\author{
Female Identities in the "Masculinized" Professional Context \\ of Civil Engineering in Southwestern Colombia
}

Recibido: 26 de septiembre de 2017 - Revisado: 2 de octubre de 2018 - Aceptado: 15 de enero de 2019

Oscar Martin Rosero Sarasty ${ }^{2}$

\begin{abstract}
Resumen
Los enfoques de Stuart Hall y de Michel Foucault sobre la sujeción y la subjetivación permiten el análisis de las identidades femeninas. A partir de allí, se analizaron los procesos de construcción de identidades de mujeres ingenieras en una profesión de hegemonía masculina: la ingeniería civil. Se utilizó el método cualitativo y las historias de vida de quince ingenieras graduadas en universidades del suroeste colombiano que permitieron cuestionar la presencia de mujeres en este campo profesional. Como resultados y conclusiones se encontró que las identidades se construyen como rutas discursivas particulares con posiciones diversas que utilizan prácticas institucionalizadas de hegemonía masculina, pero también de auto-reconocimiento, valoración y re significación de la contribución de las mujeres en la profesión y su ubicación en la sociedad
\end{abstract}

\section{Palabras clave}

Identidad, género, identidades femeninas, sujeción, subjetivación, ingenieras.

\begin{abstract}
Stuart Hall's and Michel Foucault's approaches to subjection and subjectification allow the analysis of female identities. This research aimed to analyze the identity construction processes of female engineers in a profession of male hegemony such as civil engineering. Using a qualitative methodology and life stories of 15 female engineers who had graduated from universities in southwestern Colombia, it was found that identities are constructed as particular discursive routes with diverse positions that carry out institutionalized practices of masculine hegemony but also of self-recognition, valuation and resignification of the contribution of women in the profession and their position in the society.
\end{abstract}

\section{Keywords}

Identity, gender, feminine identities, subjection, subjectivation, engineers.

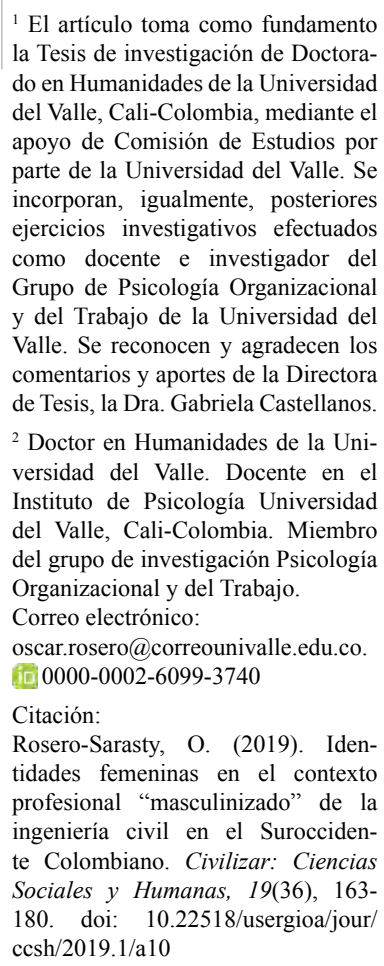

${ }^{1}$ El artículo toma como fundamento la Tesis de investigación de Doctorado en Humanidades de la Universidad del Valle, Cali-Colombia, mediante el apoyo de Comisión de Estudios por parte de la Universidad del Valle. Se incorporan, igualmente, posteriores ejercicios investigativos efectuados como docente e investigador del Grupo de Psicología Organizacional y del Trabajo de la Universidad del Valle. Se reconocen y agradecen los comentarios y aportes de la Directora de Tesis, la Dra. Gabriela Castellanos.

${ }^{2}$ Doctor en Humanidades de la Universidad del Valle. Docente en el Instituto de Psicología Universidad del Valle, Cali-Colombia. Miembro del grupo de investigación Psicología Organizacional y del Trabajo.

Correo electrónico:

oscar.rosero@correounivalle.edu.co. ib 0000-0002-6099-3740

Citación:

Rosero-Sarasty, O. (2019). Identidades femeninas en el contexto profesional "masculinizado" de la ingeniería civil en el Suroccidente Colombiano. Civilizar: Ciencias Sociales y Humanas, 19(36), 163180. doi: 10.22518/usergioa/jour/ $\operatorname{ccsh} / 2019.1 / \mathrm{a} 10$ 


\section{Introducción}

Las últimas décadas de la vida social contemporánea podrían caracterizarse, siguiendo a Harvey (1998), por "una metamorfosis en las prácticas culturales, económicas y políticas" (p. 9) con cambios y cuestionamientos sobre las formas de comprender y de vivir la vida; establecer metas, propósitos, formas de relación y sentidos para la misma (Hall, 2003; Restrepo, 2009). A la par, cobra fuerza la confrontación de las categorías de sujeto, subjetividad (Foucault, 1972; Lyotard, 1994; 1995) y la de identidad; en especial si ésta se ha pensado bajo presupuestos de permanencia, coherencia de una esencia, principio o núcleo fijo e inmutable (Gergen, 1997; Harvey,1998; Hall, 2003). Se suman al debate académico aquellas transformaciones que tienen lugar en la organización laboral a nivel mundial, donde cobra fuerza el denominado tránsito del modelo fordista hacia el de acumulación postindustrial y flexible (Antunes, 2000; 2009; Bauman, 1999; Bensusán, Eichhorst y Rodríguez, 2017; Castells, 2000; Castells y Himanen, 2014; Harvey, 1998; Offe, 1984; Scocco, 2018; Torres, 2013). En este marco, los debates sobre la identidad parecen adquirir importancia estratégica y dan lugar a la constitución de variados asuntos de investigación vinculándola con problemas de la modernidad y sus transformaciones e impactos en lo sujetos contemporáneos (Giddens, 2000); relaciones con cultura y política (Castellanos, Grueso y Rodríguez, 2009) y problematizaciones vinculadas a los conceptos de etnia, raza (Gómez García, 2000) y derechos humanos (Pérez Tapias, 2000). Entre tales asuntos, cobra particular interés el estudio de las identidades femeninas articuladas a los contextos de trabajo (Hirata y Kergoat, 1998; Arango L. G., 2006; Bermúdez, 2007). Más cuando diversas corrientes en los estudios de las mujeres y del género han logrado evidenciar que el trabajo humano, considerado durante muchos años el eje articulador de la vida personal y social y referente central de la identidad en la modernidad, también ha sido uno de los contextos de mayor discriminación y opresión para las mujeres (Arango, 1991; 1995; Arango, Viveros y Bernal, 1995; Bergesio, 2006; Bermúdez, 2007; Camacho, 2006; Federici, 2013; Guirao Mirón, 2011; Guzmán, Todaro y Godoy, 2017; Hirata y Kergoat, 1998; Maciel Noyola, Ruíz Martínez y Cruz Cabrera, 2016; Rodriguez Pizarro e Ibarra Melo, 2013; Rubin, 2003; Scott, 2000; Scocco, 2018; Tereso Ramírez y Cota Elizalde, 2017).

El análisis del trabajo humano desde una perspectiva de género exige, como lo proponen distintas teorías e investigadoras, tomar en consideración que históricamente las mujeres han sufrido opresión por su condición de género (Scott, 1990; Urrea, 1994; Bourque, Conway y Scott, 1998; Lamas, 2003). En tal sentido, resulta fundamental comprender que la masculinización de la ingeniería civil evidencia la continuidad de viejas prácticas y miradas androcéntricas que han promovido la división sexual del trabajo que se sustentaba a su vez en supuestas fortalezas masculinas y deblidades femeninas derivadas del sexo y de la biología; esto permitió que se institucionalizaran como asuntos naturales diversos dispositivos de relación y regulación social (Hirata y Kergoat, 1998; Burin y Meler, 2005).

En la actualidad, pese a que han sido muchos los cuestionamientos a la división sexual del trabajo y las consecuentes prácticas de $d o$ minación masculina de allí derivadas (Bourdieu, 2000; Valcuende del Rio y Blanco López, 2015) bajo sus implicaciones discriminatorias y excluyentes que impactan, en principio, a las mujeres, se siguen manteniendo categorías de trabajo feminizadas y masculinizadas (Arango, 2004), situación que en la práctica se refleja con frecuencia en el número de mujeres versus el número de hombres que ingresan y luego ejercen cierto tipo de profesiones. Es un hecho prominente que la presencia femenina en la ingeniería civil y en otras ramas de la ingeniería resulta muy baja frente a la alta concentración masculina. Así las cosas, muchas mujeres viven relaciones asimétricas y jerarquizadas que, en 
contextos masculinizados como los del trabajo profesional en ingeniería, conllevan prácticas de dominación y exclusión que precisan visibilizarse, explicarse y superarse. Este tipo de situación exige tomar con cautela y sentido crítico situaciones y datos del trabajo femenino en Colombia y, sobre todo, lo que se vincula con la formación profesional universitaria; si bien, las cifras de mujeres han aumentado en las últimas décadas y se ha generado lo que algunos denominan como feminización de la educación superior, resulta dudoso plantear que con esto se hayan logrado resolver las profundas asimetrías y desventajas que afectan a las mujeres, en especial en sectores profesionales en los que predomina la figura masculina, como ocurre en la ingeniería civil (Correa, 2005; Daza, 2010).

Bajo esta perspectiva, las investigaciones de Alcoff (2002), Bartky (2008) y Butler (2001), que se detallan más adelante, han generado valiosos aportes acerca de la condición diferenciada de la mujer en los procesos de constitución de sus identidades al visibilizar la existencia de determinaciones históricas y culturales de opresión que han mostrado herramientas existentes que les permiten a las mujeres actuar como agentes capaces de movilizar normas de género, así como sus subjetividades e identidades.

Ante situaciones como las descritas, el propósito investigativo se encamina en comprender las formas particulares mediante las cuales mujeres ingenieras ponen en juego y construyen sus identidades al afrontar condiciones de acceso, permanencia y desempeño profesional propias de un contexto masculinizado como el que se presenta en el campo de la ingeniería civil. En consecuencia, resulta fundamental analizar los discursos de saber y poder en dicha profesión y cómo éstos se articulan con formas particulares de posicionamiento, relaciones e interacciones que las ingenieras establecen como formas de auto-constitución de sí mismas.
Los planteamientos de Hall (2003) y la doble condición de sujeción/subjetivación propuesta por Foucault (1991) para la constitución de posiciones de sujetos y subjetividades sirve de fundamento de la investigación al contemplar que las identidades deben pensarse como un punto de encuentro "entre procesos institucionales que asignan determinados lugares a los sujetos y aseguran formas de sujeción y aquellos de subjetivación que el sujeto desarrolla encaminados a la auto-constitución de sí mismo" (Hall, 2003, p. 20). Esta propuesta de articulación y sutura dinámica entre posiciones de discursos institucionalizados y prácticas de auto-constitución conlleva a la revisión de planteamientos de Foucault acerca de discursos, prácticas discursivas (Foucault, 1972; 1992b; 2008), relaciones de poder (Foucault, 1991; 1992a; 2003; 2005) y procesos de subjetivación (Foucault, 1998; 1999b), asuntos que ayudan a visualizar las identidades como construcción y articulación de procesos de sujeción y subjetivación.

El discurso, de acuerdo con Foucault (1972), tiene un carácter histórico y debe ser entendido como "prácticas que forman sistemáticamente los objetos de que hablan" (p. 81). Las prácticas discursivas son vistas por Foucault (1972) como un "conjunto de reglas anónimas, históricas, siempre determinadas en el tiempo y el espacio que han definido en una época dada, y para un área social, económica, geográfica o lingüística dada, las condiciones de la enunciación" (p. 192). Los discursos y prácticas hacen posible la emergencia y acción continua de un haz de relaciones donde emergen las subjetividades, las posiciones para los sujetos.

La problemática del poder presenta también formas de sujeción y emerge como la posibilidad de otro tipo de formaciones de subjetividades y sujetos que recurren a otros medios y recursos (Deleuze, 1987). Con la anatomo-política tiene lugar el desarrollo de procedimientos de poder característicos de las disciplinas, se concibe el cuerpo como máquina que se ha 
de intervenir a fin de asegurar utilidad y docilidad; lo mismo que su integración en sistemas de control eficaces y económicos (Foucault, 2005). Se trata, en palabras de Foucault (2005), de una modalidad microfísica de poder que "implica una coerción ininterrumpida, constante, que vela sobre los procesos de la actividad más que sobre su resultado y se ejerce según una codificación que reticula con la mayor aproximación el tiempo, el espacio y los movimientos" (p. 141).

La biopolítica, según Foucault (2003) "hace entrar la vida y sus mecanismos en el dominio de los cálculos explícitos y convierte al poder-saber en un agente de transformación de la vida humana" (p. 173). En su conjunto, anatomo-política y biopolítica constituyen el bio-poder que, según propone Foucault (2003), resultó indispensable para el desarrollo del capitalismo, el cual "no pudo afirmarse sino al precio de la inserción controlada de los cuerpos en el aparato de producción y mediante un ajuste de los fenómenos de población a los procesos económicos" (p. 170). Con la consolidación del bio-poder, según lo analiza Foucault (2003), se procura entonces alcanzar los más recónditos lugares de la vida humana para "administrarla, aumentarla, multiplicarla, ejercer sobre ella controles precisos y regulaciones generales" (p. 165).

Ahora bien, en lo que corresponde a las prácticas de subjetivación, es decir, aquellas que pueden dar lugar a la auto-constitución de los sujetos, es interesante observar el giro que registran las últimas obras de Foucault. Si bien se mantiene la idea antiesencialista sobre el sujeto, el autor parece percatarse de que si se sobreestima el poder disciplinario y éste se asume como una fuerza monolítica que satura todas las relaciones sociales, en correlación, se empobrece al individuo sin poder dar cuenta de sus experiencias, en especial de aquellas ajenas al reino de los cuerpos dóciles (Hall, 2003; Rodríguez, 1999). Ante este tipo de cuestiones, Foucault (1998) entra a considerar que del lado del sujeto pueden contemplarse prácticas de subjetivación que los constituyen, prácticas por las que afirma que:

Los individuos se ven llevados a prestarse atención a ellos mismos, a descubrirse, a reconocerse y a declararse como sujetos de deseo, haciendo jugar entre unos y otros una determinada relación que les permita descubrir en el deseo la verdad de su ser. (p. 9).

Con los procesos de subjetivación, explica Deleuze (1987), Foucault logra entonces dar cuenta de una dimensión que si bien deriva del poder y del saber, no depende de ellos. La relación consigo mismo se configura a manera de pliegue o doblez cuyo adentro se constituye a partir del afuera. Foucault (1998) propone, por lo tanto, que los procesos de constitución del sujeto, y podría pensarse entonces que también los proceso de construcción de identidades, pueden variar apoyados en prácticas diferenciadas sobre asuntos tales como la determinación de la sustancia ética, es decir, la "manera en que el individuo debe dar forma a tal o cual parte de sí mismo como materia principal de su conducta moral" (p. 27). Pueden ocurrir diferenciaciones a partir de los modos de sujeción, es decir, por "la forma en que el individuo establece su relación con esta regla y se reconoce como vinculado con la obligación de ponerla en obra" (p. 28). Otro tipo de diferencias en los mencionados procesos de auto constitución que propone Foucault (1998) pueden surgir en las formas de elaboración del trabajo ético realizado en uno mismo "no solo para que nuestro comportamiento sea conforme a una regla dada sino para intentar transformarnos nosotros mismos en sujeto moral de nuestra conducta" (p. 28). Para la constitución de un modo de ser característico es importante, así mismo, la teleología del sujeto moral como posibilidad de reconocer una acción más allá de su singularidad, "por su inserción y lugar en el conjunto de una conducta; [por ser] un elemento, un aspecto que señala una etapa en su duración, un progreso eventual en su continuidad" (p. 28). 
Con lo planteado hasta el momento, y conforme a los resultados de esta investigación, se observará que los desplazamientos conceptuales de Foucault (1998) resultan de gran interés y pertinencia, ya que brindan un panorama complejo de los procesos de constitución de subjetividades y sujetos, y de las identidades pensadas como procesos de encuentro que tienen lugar bajo contextos culturales e históricos específicos (Hall, 2003, p. 31).

Ahora bien, a estos postulados Foucaultianos, que pueden resultar de interés para el estudio de las identidades, se suman aportes valiosos de Butler (2001; 2002; 2006a; 2006b), Alcoff (2002) y Bartky (2008), quienes contemplan condiciones especiales que genera la condicion de género en los procesos de constitución de subjetividades e identidades femeninas. Así, por ejemplo, a partir de los postulados de Foucault, Butler (2002) enfatiza en que el poder, además de sus funciones prohibitivas, conlleva también opciones generativas. Bajo tal perspectiva, la identidad para Butler (2001) se constituye entonces mediante las diferentes prácticas reguladoras de la formación y división del género, y actúa como ideal normativo más que como un rasgo descriptivo de la experiencia. Asuntos de coherencia y continuidad antes que rasgos lógicos o analíticos de la calidad de la persona son normas de inteligibilidad instituidas y establecidas en la sociedad. Por lo anterior, antes que pensar la identidad personal, se ha de considerar la identidad de género como su base, pues las personas "solo se vuelven inteligibles cuando adquieren un género ajustado a normas reconocibles de inteligibilidad de género" (p. 49). En esa medida, sexo, género, deseo y sexualidad actúan a manera de conceptos estabilizadores, y son sus relaciones de coherencia y continuidad, vistas bajo el marco de un heterosexualismo hegemónico, las que aseguran condiciones de inteligibilidad e identidad.

La invitación de Butler ante este tipo de lógicas sustentadas en condiciones dominantes de poder se orienta no a la búsqueda de estra- tegias utópicas fuera de los marcos del mismo poder, sino a la revisión de los parámetros y operaciones políticas de la construcción del "ser" del género. Del análisis de sus procesos constitutivos, de su construcción discursiva y performativa y de la observación de su multiplicidad se pueden obtener elementos que permitan resignificar la identidad y las categorías que la sustentan si se consideran opciones de desplazamiento y subversión para las mismas. Las identidades como prácticas discursivas y performativas han de asumirse entonces como permanentemente abiertas a la intervención y resignificación. Esa apertura a múltiples experiencias de significación impone requerimientos para las mujeres, pero a la vez les ofrece posibilidades para construir y asumir posiciones que respeten su especificidad y la capacidad de actuar como agentes capaces de aceptar o rechazar tales requerimientos.

Por su parte, Alcoff (2002) considera que las cuestiones del sujeto y en especial la acción de conceptuar a la mujer son asuntos que, además de implicar lo empírico, están atravesados por argumentaciones e implicaciones éticas y políticas. Bajo tal perspectiva propone, en primera instancia, asumir el género como "una interpretación de nuestra historia en una constelación discursiva particular; una historia en la que somos sujetos y estamos sujetos a la construcción de la sociedad" (p. 17). Luego de las tesis esencialistas acerca de la subjetividad e identidad de las mujeres, la subjetividad marcada por el género, propone Alcoff, debe relacionarse con "costumbres, hábitos y discursos concretos y a la vez aceptar su carácter mudable" (p. 18). Es preciso insistir en la dimensión histórica y situada de la subjetividad al aceptar que muchas conclusiones tienen un carácter contingente, pertinente para lugares, situaciones y contextos puntuales.

En ese sentido, según Alcoff (2002), el concepto de posiciones contempla una doble vertiente para el concepto de mujer, ya que conlleva pensarla como un término relativo, 
inmerso en un contexto de movimiento y se debe considerar su posición como un lugar o emplazamiento que puede utilizarse para construir la feminidad y no para descubrirla como si fuera algo ya dado. En tal sentido, la identidad de la mujer se encuentra entrelazada con un flujo constante de condiciones e instituciones económicas, culturales, políticas, sociales e históricas; se comprende entonces que las posiciones que asumen las mujeres no son innatas, pero tampoco son indeterminadas, se trata más bien de posiciones relativas, contingentes, fluctuantes.

Los aportes de Bartky (2008) resultan importantes para la reflexión de las identidades femeninas, dicha autora cuestiona y enriquece los análisis de Foucault al criticar que éste se haya referido al disciplinamiento del cuerpo sin asumir la diferenciación existente en cuanto a experiencias corporales entre hombres y mujeres. Foucault, propone Bartky (2008), "habla del cuerpo como si fuera uno, como si las experiencias de hombres y mujeres no difirieran, y como si los hombres y las mujeres tuvieran la misma relación con las instituciones características de la vida moderna" (p. 139). Bartky postula entonces la existencia de disciplinamientos culturales que generan una incorporación particularmente femenina. Se pueden considerar al menos tres categorías específicas de disciplinamientos: (a) aquellos que buscan producir un cuerpo de cierto tamaño y configuración; (b) aquellos que extraen del cuerpo un repertorio de gestos, posturas y movimientos; (c) aquellos dirigidos hacia la exhibición del cuerpo como una superficie ornamentada.

Por todo lo que implica el proyecto disciplinario de la feminidad, la subjetividad femenina en la actualidad se encuentra matizada por este tipo de condiciones que se ejercen en especial sobre el cuerpo femenino. Se trata de una disciplina no igualitaria, una disciplina amplia, que bajo un sistema desigual y opresivo de subordinación sexual, que en muchos casos confluye además con asuntos de raza, clase social y etnia, produce un cuerpo sometido y practicado, un cuerpo inferiorizado.

\section{Investigación y resultados}

La investigación se asume bajo una perspectiva cualitativa que intenta superar tendencias generalizantes bajo las cuales se tiende a simplificar la compleja realidad social y se excluyen de paso situaciones diferentes atípicas, que pueden conllevar diversas formas de exclusión (Bonilla y Rodríguez, 1997; González, 2007). Se trabajó, además, con el método de relatos de vida pensándolos como formas narrativas que articulan experiencias particulares con condiciones estructurales (Bertaux, 2005; Kornblit, 2007). Se entrevistó a quince ingenieras con al menos cinco años de experiencia profesional, egresadas de los cuatro programas de ingeniería existentes en el suroccidente colombiano, quienes fueron ubicadas mediante selección intencional o de conveniencia (Goetz y LeCompte, 1988; Giménez y Mallimaci, 2006). La información de las ingenieras fue contrastada y complementada con otras fuentes: compañeros de estudio, colegas de profesión y directivos del sector. Para la sistematización y análisis se utilizó el Software Atlas.Ti, con el fin de visualizar experiencias que permitieran dar cuenta de los aspectos contemplados en categorías vinculadas a los propósitos de la investigación. En la presentación de resultados, se ha optado por asumir nombres ficticios que permitan superar la simple denominación abstracta de sujetos participantes, pero que a su vez protejan la reserva de las participantes.

La investigación permitió observar que el acceso, la permanencia y, posteriormente, el desempeño profesional de las participantes en la investigación se encontraban permeados y regulados por consideraciones y prácticas socioculturales con claras incidencias en situaciones económicas. Tales prácticas se han constituido históricamente, desde allí se ha fomentado y se ha dado vigencia a la idea de que la ingeniería civil es una carrera para hombres, que resulta 
distante y ajena a las condiciones y capacidades de las mujeres. Resulta elocuente sobre este tipo de situaciones el testimonio de Mery, quien expresa las creencias que imperaban en su familia al considerar su acceso a la carrera y expresa: "mi mamá me decía que era muy dificil y que generalmente era para hombres"; o como en el caso de Ivette, cuyo padre expresó su preocupación luego de que ella manifestara su deseo por ingresar a ingeniería civil, consideraba que era "una carrera de hombres... que le parecía muy agresiva para su niña". Por su parte, Ada recuerda lo que pensaban varios de sus compañeros durante la carrera. Entre ellos se decía que: "las mujeres íbamos a la universidad a buscar marido ingeniero, que solo servíamos en posición horizontal, que habia que ayudarnos para que no nos quedemos".

Se encontró que varias ingenieras han quedado expuestas a prácticas continuas de duda y desafío ante su supuesta debilidad tanto física como intelectual. La existencia de tales ideas se corrobora en el testimonio de Leydy al recordar que en su familia se consideraba que la ingeniería "era algo para hombres [porque] los hombres son los duros en matemáticas". De la misma manera, Ada manifiesta: "algunas tías y mi abuela pensaban que las ingenieras civiles debiamos hacer trabajo de oficina... las tías paternas estaban seguras de que no sería capaz de ejercer".

\section{Discursos, prácticas de poder y sujeción}

Las consideraciones expuestas dan cuenta de configuraciones particulares de discursos que perpetuán en la ingeniería civil una evidente división sexual y en consecuencia, la exaltación del trabajador masculino y la subvaloración del trabajo femenino, que resultan vinculados y sustentan finalmente una clara polarización entre demandas de familia y trabajo, lo que afecta de manera particular a las mujeres ingenieras. Se consolidan entonces discursos y prácticas con maniobras de sujeción bajo las cuales las ingenieras por su condición de género son convocadas con frecuencia a ocupar como algo natural y cotidiano, lugares secundarios que las invisibiliza al tener baja valoración social.

Gilda expuso este tipo de situaciones; ella $\mathrm{y}$ varias de sus colegas ingenieras lo han vivido en su ejercicio profesional: "se prefiere al hombre por encima de la mujer y entre las mujeres, a la profesional soltera antes que a la casada, por su disponibilidad de tiempo...". Resultan similares los comentarios de antiguos compañeros y actuales colegas masculinos: Arturo comenta que "con gran frecuencia ellas se ven subvaloradas y en desventaja por su apariencia externa, su debilidad o apariencia física", Julio coincide en haber escuchado con bastante frecuencia comentarios que "van en el sentido de dudar de las capacidades fisicas de las mujeres en los trabajos de campo".

Delia ilustra cómo en el ejercicio profesional el trabajo de cuidado del hogar asignado por tradición como un asunto natural a las mujeres, con sus consecuentes demandas de tiempo y dedicación, afecta a las ingenieras y las sitúa en desventaja frente a sus colegas masculinos afirma: "exigen alta disponibilidad de tiempo... en esas circunstancias es más difícil para una mujer cumplir con su rol de madre y esposa y peor si la pareja no colabora y está esperando que su mujer le tenga la comida caliente, la ropa limpia y planchada y haga las tareas de los niños".

Como se observa, en este tipo de enunciaciones se mantienen y refuerzan características que se piensan inherentes a la naturaleza femenina, tácticas de poder que de manera casi imperceptible fijan límites y obstáculos, por ejemplo, a las posibilidades que tienen algunas mujeres para ocupar cargos directivos o para obtener valoración y reconocimiento socioeconómico por su trabajo y sus funciones. En tal sentido, resulta interesante la opinión de Gustavo, un colega y directivo que formula respecto a los criterios para seleccionar un 
ingeniero o ingeniera para determinados trabajos y sectores en la profesión: "para el campo, la parte técnica y desarrollo de actividades de campo, escogería a un hombre; a diario tienen que lidiar con personas intolerantes y obreros machistas. Por ello, un hombre sería más adecuado en este aspecto". Se mantienen, por lo tanto, formas de saber y poder que bajo estrechas relaciones de interdependencia ponen en evidencia la existencia de un contexto jerarquizado a partir del género, con claras ventajas para lo masculino; situación que deben enfrentar las mujeres en la ingeniería civil como parte de su cotidianidad.

Trazado el panorama de discursos, formas de saber y prácticas de poder que determinan las posibilidades de sujeción que deben afrontar las ingenieras, resulta fundamental considerar la contraparte que el mismo Foucault (1998) visualizó al considerar los procesos de auto constitución subjetiva de los sujetos, es decir, los procesos de subjetivación.

\section{Núcleos de tensión y subjetivación}

Trabajo y familia son en tal sentido dos asuntos que resultan centrales al desarrollo de formas de relación consigo mismas que establecen las ingenieras consultadas, así se configura una relación tensa y contradictoria que impone en ellas una negociación continua. El testimonio de Carolina ejemplifica dicha situación: "tuve que dejar de trabajar un año para dedicarme al cuidado del primer bebé y de la casa. En todo caso, siempre he tenido claro que primero está mi familia ante el trabajo...".

Frente a ese núcleo socio-cultural y tradicional que impone y obliga a asumir lo femenino ligado a lo materno, el ejercicio profesional determina la implementación de formas particulares de relación de las ingenieras consigo mismas. Carmen sostiene, por ejemplo, que "es una profesión que me gusta mucho, es constante cambio y reto para la existencia"; de igual manera, Mariana ratifica todas estas apreciacio- nes al afirmar que "para mí este trabajo es una pasión y me encanta lo que hago y me encanta mi especialidad". En este aspecto, es importante señalar también que las mujeres ingenieras adoptan ciertos ideales de realización personal y profesional propios de esa visión económica de éxito ligado a un sujeto empresario de sí mismo.

Paradójicamente, los propósitos y metas particulares de las ingenieras se presentan ligados al reconocimiento y estatus que comporta estudiar y ejercer algo que socialmente se ha delegado a los hombres y que además se considera una buena carrera, puesto que ofrece la posibilidad de satisfacer unas expectativas económicas, lograr una movilidad social y satisfacer ciertos ideales de éxito. Mariana, por ejemplo, resalta una consideración de varias de sus colegas al recordar la sensación de importancia y satisfacción que produce el ser ingeniera civil:

"La ingeniería es un trabajo que, como tú, eres casi que única, o eres de las pocas mujeres que la ejercen, tú te sientes bien... para mi que hubiera muchos hombres y pocas mujeres era motivo de orgullo, era motivo de satisfacción..."

Delia, por su parte, sostiene que: "la ingeniería también ha sido la forma en que me he ganado la vida honestamente y me ha permitido vivir digna y cómodamente".

El gusto y la motivación por la profesión se vinculan con la posibilidad de ejercer funciones de liderazgo bajo connotaciones particulares, así como manejar situaciones de mando e interrelaciones con subalternos que pueden asumirse bajo acciones de creatividad que podrían ir más allá de tradiciones androcéntricas y que en tal caso no pueden pensarse como asuntos reservados de los hombres.

Carolina ayuda a visualizar este tipo de situación, comenta: "en mi caso siempre he manejado mis relaciones con un buen trato y 
dando órdenes sin entrar en choque con los obreros. Las mujeres somos mejores negociadoras". En ese sentido, Delia afirma: "creo que para que las personas funcionen no hay necesidad de 'madrazos'o gritos; de hecho, [los obreros] prefieren que yo los corrija a que lo haga alguno de mis jefes, son más duros".

Otro aspecto vinculado con el proceso de constitución de sí mismas, presente en las enunciaciones de las ingenieras, tiene que ver con formas particulares de relación que establecen con las reglas sociales y el reconocimiento que ellas hacen con la obligación de su acatamiento y ejecución. Al respecto, se pudo observar que pese a prejuicios sociales y preocupaciones derivadas de ese poder dominante de hegemonía masculina, presentes en las consideraciones de algunos padres y en el grupo social de las ingenieras, ellas logran resistir, desacatar y resignificar esa forma de poder que las somete para lograr ingresar a una carrera negada para el sector femenino. En tal sentido, la posición femenina controvierte y resignifica concepciones acerca de las mujeres y sus relaciones, por ejemplo, con la ciencia y particularmente con las matemáticas, ya que con su permanencia en la carrera y posterior ejercicio profesional demuestran con suficiencia que no pueden seguir siendo pensadas como seres inferiores que difícilmente podrían ser aceptadas y formar parte de ese mundo de rigor científico que de manera restrictiva reservaba a la figura masculina los lugares de protagonismo.

\section{Discusión}

Es importante recordar desde Foucault (1972; 1998) la capacidad que se asigna a los discursos para producir los objetos de los que hablan. Además, según el mismo autor (2005), también se debe comprender que el discurso marca la confluencia de saber y poder y que por ende "no existe relación de poder sin constitución correlativa de un campo de saber, ni de saber que no suponga y no constituya al mismo tiempo relaciones de poder" (p. 34). A la luz de estos postulados es importante precisar, además, como lo propone Rodríguez (1999), que si bien Foucault no estuvo interesado en discernir dentro de su teoría las asimetrías propias de las relaciones de género, sus postulados y análisis históricos del discurso y sus análisis de la problemática del poder contribuyen a hacer explícitas formas de control y poder presentes a partir del género en distintos tipos de discursos.

Por ejemplo, en el caso de la ingeniería civil la división sexual del trabajo encarna una situación social de extendida trayectoria que lleva implícitos diversos mecanismos de poder con formas de regulación y control social (Arenas Ramiro, 2011; Bensusán, Eichhorst y Rodriguez, 2017; Burin y Meler, 2005; Hirata y Kergoat, 1998; Moore, 1991). Esa división sexual encuentra sustento en esa larga tradición sociocultural y en un conjunto de prácticas consecuentes que como explica Arango (2006), permiten "reafirmar y confirmar la mayor habilidad de los varones para esta profesión y las dificultades de las mujeres para desempeñarla a cabalidad" (p. 249). Tal ubicación, por supuesto, resulta de consideraciones históricas contrapuestas de tipo social, cultural, económico $\mathrm{y}$ moral que al mismo tiempo han fomentado las imágenes masculinas de extroversión, fuerza, liderazgo, inteligencia, racionalidad y autonomía; han reforzado también aquellas ideas sobre la fragilidad femenina y sobre la naturaleza maternal y cuidadora de las mujeres (Arango L. G., 2006; Molinier, 2011; Fernández, 2004; Fernández Tijero, 2016; Otalvaro-Marin, Ceballos-Molano, Bonilla-Mejía, y Gómez, 2018).

Sobre estos asuntos es importante considerar, como lo analizan Lisbona, López y Saínz (2004), que "la socialización diferencial y estereotipada de niñas y niños influye en la identidad social y personal y en la interiorización de una serie de creencias sobre uno mismo y de expectativas por el hecho de ser hombre o mujer" (p. 161). Tales creencias y expectativas, y las percepciones sobre la valoración social de determinadas profesiones constituyen impor- 
tantes mecanismos de "regulación y control social” (Lisbona, López y Saínz, 2004, p. 162). Se muestran coincidentes con este aspecto las investigaciones de Gutiérrez (2010) que con estudiantes de ingeniería en México ratificaban la "discriminación por parte de sus maestros y las burlas de sus compañeros por el hecho de ser mujer y estudiar ingeniería” (p. 9).

Arango (2011) analiza que el silencio conceptual de diversos campos sociales y académicos en torno al trabajo doméstico ha tenido mucho que ver en la constitución de este tipo de situaciones, , lo cual contribuye "al ocultamiento y la negación de todo valor social (económico y moral) a las horas de trabajo, desgaste físico y mental, a las oportunidades perdidas para la educación y la promoción profesional de numerosas mujeres" (p. 96).

En el caso de la ingeniería civil, el peso de las responsabilidades del cuidado del hogar y la familia son confrontadas. Por lo tanto, las responsabilidades del trabajo se ponen de manera casi exclusiva sobre las espaldas de las ingenieras por su condición de mujeres y en esto tiene mucha influencia el conjunto de tradiciones arraigadas en lo que se ha identificado como el "mito de la mujer cuidadora" (Fernández Tijero, 2016; Molinier, 2011; Organización Internacional del Trabajo Programa de Desarrollo las Naciones Unidas OIT- PNUD, 2008). El acatamiento de preceptos sociales bajo los cuales se define como prioridad el cuidado de los hijos y la familia lleva incluso a contemplar lo materno y el cuidado como la realización o frustración de la condición femenina y de mujer. La vigencia de tal tipo de consideraciones, según lo indica Carrasco (2003), no hace más que poner en evidencia que, pese a que muchas mujeres en la actualidad han logrado integrarse al ámbito público y se ha producido su incorporación masiva al sistema educativo y laboral, este tipo de cambios "no han tenido eco en el resto de la sociedad... y en consecuencia, el funcionamiento social no ha experimentado transformaciones sustanciales y los efectos de la nueva situación han tenido que ser asumidos por las propias mujeres" (p. 24). Ante la ambigüedad y las tensiones de familia y trabajo, las mujeres ingenieras sin duda siguen muy solas y se ven obligadas a asumir los sacrificios y costos que tales situaciones conllevan.

Ahora bien, al tratar de comprender cómo se mantienen y operan mandatos socioculturales de corte sexista, como los que hasta el momento se han referido, los aportes de Butler (2001; 2002) acerca de la performatividad resultan esclarecedores. Se entiende bajo las consideraciones de esta autora que los mandatos socioculturales con las consecuentes formas de saber y poder que estos encarnan, surgen y se legitiman mediante la presencia reiterativa de formas que se repiten a diario; situaciones que para la presente investigación se ven reflejadas con frecuencia en los discursos de colegas y directivos, quienes manifiestan que la escogencia para cargos directivos se encuentra influenciada por consideraciones que ponen en desventaja a las mujeres.

Desde allí, tal como lo propone Butler: "la anticipación conjura su objeto" (p. 15), pues las supuestas debilidades y diferencias que se atribuyen a las mujeres por su condición de género para el ejercicio de autoridad en la ingeniería civil se materializan y consolidan obligatoriamente en función de las expectativas generadas por la incapacidad física o académica, atribuida culturalmente a la mujer, lo mismo que por la disposición natural para la ingeniería, atribuida también a los hombres.

Frente a los discursos de poder y prácticas de sujeción del contexto masculinizado, familia y trabajo son dos asuntos que aparecen como núcleos preponderantes de subjetivación, es decir, de relación consigo mismas que adoptan las mujeres ingenieras de la investigación que resultan determinantes para sus identidades. Se observa entonces una relación de tensión que obliga a prácticas constantes de cambio, pues ante ese núcleo de lo femenino-materno visto 
como asunto natural y sobre todo determinante en la realización personal y de la identidad como mujeres, los asuntos del trabajo y del ejercicio profesional se configuran como el otro polo determinante que demanda constantemente la implementación de formas particulares de relación y adopción de prácticas específicas sobre sí.

Carrasco (2003) propone que las mujeres deben entonces transitar continuamente entre trabajo y familia como ámbitos de naturaleza distinta, al pasar de:

Unas características específicas de la actividad familiar a unos horarios y valores del trabajo; de una cultura del cuidado a una cultura del beneficio; todo lo cual les exige interiorizar tensiones, tomar decisiones y hacer elecciones a las cuales los varones no están obligados. (p. 27).

En este aspecto, es importante señalar que las mujeres ingenieras no escapan a ciertos ideales de realización personal y profesional que, como lo analizan Du Gay (2003) y Rose (2003), se configuran en la contemporaneidad bajo las imposiciones propias de esa visión económica de sujeto empresario de sí mismo.

Otro aspecto vinculado con el proceso de constitución de sí mismo tiene que ver con lo que Foucault (1998) denominó los modos de sujeción, formas particulares de relación que, en este caso, establecen las ingenieras con las reglas sociales y que se relacionan con el reconocimiento que ellas hacen con la obligación de su acatamiento y ejecución. Se comprende así que las mujeres ingenieras construyen sus subjetividades e identidades como una "práctica que está sucediendo [permanentemente y por lo tanto], está abierta a la intervención y a la resignificación" (p. 67). Es decir, el poder prohibitivo que reitera día a día saberes y prácticas de dominación puede derivar también en formas generativas que subvierten las pautas impuestas por el mismo poder.
En ese mismo sentido, la presencia femenina controvierte y resignifica entonces, según lo analiza Perdomo (2009), concepciones que han regido el pensamiento occidental acerca de la relación entre las mujeres y las áreas de matemáticas y en general con la ciencia moderna, en especial si dichas mujeres son concebidas como seres en déficit que apenas podrían ser aceptadas y formar parte de ese mundo de rigor científico que reservaba a los hombres los lugares de protagonismo.

\section{Conclusiones}

Es importante destacar que la prevalencia de un panorama masculinizado, como se ha evidenciado en el caso de la ingeniería civil, no puede llevar a pensar que las identidades de las mujeres se configuran a merced de las fluctuaciones y determinaciones del ambiente y en contextos de dominación y subvaloración que allí puedan imponerse. Bajo las condiciones antes mencionadas se puede afirmar que las identidades de las ingenieras no pueden contemplarse tan solo en su visualización como mujeres eternamente sumisas o, por el contrario, en la idealización de figuras de heroínas de rebeldía, sino en la vivencia personalizada y específica de confrontación de situaciones reales de dominación que cada una debe afrontar y que, no obstante su hostilidad, aún son susceptibles también de resignificación. Para el caso que nos ocupa, la profesión de ingeniería civil no solo se configura como un panorama de limitaciones, restricciones y controles, sino que convoca el cambio y propone retos para la existencia de las mujeres investigadas y para el cambio social. Las ingenieras se posicionan y logran configurar sobre sí mismas imágenes que marcan rumbos de renovación personal y profesional que ayudan a superar ubicaciones secundarias e invisibles en la profesión.

Vale la pena considerar la propuesta de Alcoff (2002), que al referirse a la mujer observa que ella no está determinada: 
Únicamente por los elementos externos, ni es el recipiente pasivo de una identidad creada por estas fuerzas. Más bien ella misma forma parte del movimiento de una historia fluctuante y por tanto contribuye activamente a crear el contexto en el que puede delinearse su posición. (p. 19).

Las identidades de las ingenieras se conjugan, por lo tanto, en un marco dinámico donde se presentan discursos de poder con prácticas de exclusión e impacto para la participación en ciertos sectores de trabajo, en formas de vinculación, en la existencia de relaciones tensas entre trabajo y familia, con disyuntivas difíciles de resolver y la demanda de sacrificios que afectan en especial a las mujeres; pero se articulan también con posibilidades de desacato, resistencia, reconocimiento, estatus y realización personal. Esta amplia y compleja gama de situaciones deben ser resueltas por las ingenieras para pensarse a sí mismas, para asumir su desempeño profesional y sobre todo para construir sus identidades. Tales identidades, así como los recursos, estrategias y el posicionamiento que involucran, no son asuntos estáticos ni necesariamente excluyentes, pueden variar, alternarse y presentarse en forma paradójica, tal vez contradictoria o incluso complementaria. Esto dependerá de las condiciones históricas y de los momentos particulares de las vidas de las ingenieras, de las situaciones sociales y culturales de los contextos en los que ellas deben desempeñarse, también en sus expectativas y propósitos personales y profesionales.

Para concluir este análisis, es importante recalcar que la ingeniería como profesión impone sin duda difíciles condiciones para la presencia femenina, que resultan determinantes para perpetuar formas de dominación y exclusión de las mujeres. Esto, sin embargo, no niega la posibilidad de configurar nuevas posibilidades de constitución de identidades con alternativas de reconocimiento, valoración, resignificación del aporte de las mujeres en la profesión y de su ubicación en la sociedad.

\section{Referencias}

Alcoff, L. (2002). Feminismo cultural vs. postestructuralismo: la crisis de identidad de la teoría feminista. Revista Debates, (76), $18-41$.

Antunes, R. (2000). Adeus ao trábalo. Sao Paulo, Brasil: Editora Cortés.

Antunes, R. (2009). Diez tesis sobre el trabajo del presente (y el futuro del trabajo). En C. Consejo Latinoamericano de Ciencias Sociales (Ed.), Trabajo, empleo, calificaciones profesionales, relaciones de trabajo e identidades laborales. (pp. 29-44). Recuperado de http://biblioteca.clacso. edu.ar/clacso/gt/20160216040822/04.pdf

Arenas, M. (2011). Brecha digital de género: la mujer y las nuevas tecnologías. Anuario Facultad de Derecho Universidad de Alcali. Recuperado de http://hdl.handle. net/10017/9843

Arango, L. G. (2011). El trabajo de cuidado: ¿servidumbre, profesión o ingeniería emocional? En L. Arango, y P. Molinier (Eds.), El trabajo y la ética del cuidado (pp. 91-109). Medellín, Colombia: La Carreta.

Arango, L. G. (2006). Jóvenes en la universidad: género, clase e identidad profesional. Santa Fe de Bogotá, Colombia: Siglo del Hombre, Universidad Nacional de Colombia.

Arango, L. G. (2004). Mujeres, trabajo y tecnología en tiempos globalizados. Cuadernos del CES, (5), 1-20.

Arango, L. G. (1991). Mujer, religión e industria. Fabricato 1923-1982. Medellín, Colombia: Universidad de Antioquia, Universidad Externado de Colombia.

Arango, L. G. (1995). Identidad femenina, identidad obrera: La proletarización de la mujer en Francia en el siglo XIX. En L. G. Arango, M. León, y M. Viveros (Eds.), Género e Identidad (pp. 213-237). Santa 
Fe de Bogotá, Colombia: Tercer mundo editores, Ediciones Uniandes, Universidad Nacional Facultad de Ciencias Humanas.

Arango, L. G., Viveros, M., y Bernal, R. (1995). Mujeres ejecutivas. Dilemas comunes alternativas individuales. Santa $\mathrm{Fe}$ de Bogotá, Colombia: Ediciones Uniandes, Ecoe.

Bartky, S. L. (2008). Foucault, la feminidad y la modernización del poder patriarcal. La manzana de la discordia, 3(1), 137152. doi: 10.25100/lamanzanadeladiscordia.v3i1.1493

Bauman, Z. (1999). Trabajo, consumismo y nuevos pobres. Barcelona, España: Gedisa.

Bensusán, G., Eichhorst, W., y Rodríguez, J. M. (2017). Las transformaciones tecnológicas y sus desafios para el empleo, las relaciones laborales y la identificación de la demanda de cualificaciones. Santiago: Comisión Económica para América Latina y el Caribe -CEPAL y Ministerio de Asuntos Exteriores de Noruega.

Bertaux, D. (2005). Los relatos de vida. Perspectiva etnosociológica. Barcelona, España: Bellatera.

Bergesio, L. (2006). Mujeres visiblemente invisibilizadas: la antropología y los estudios de la división sexual del trabajo. Revista Temas de Mujeres, (2), 1-17.

Bermúdez, R. E. (2007). Mujeres obreras e identidades sociales Cali 1930-1960. Cali, Colombia: La Carreta editores, Universidad ICESI.

Bonilla, E., y Rodríguez, P. (1997). Más allá del dilema de los métodos. La investigación en ciencias sociales. Santa Fe de Bogotá, Colombia: Editorial Norma.

Bourdieu, P. (2000). La dominación masculina. Barcelona, España: Anagrama S.A.
Bourque, S., Conway, J., y Scott, J. (1998). El concepto de género. En M. Navarro y C. Stimpson (Eds.), ¿Que son los estudios de mujeres? (pp. 167-178). Buenos Aires, Argentina: Fondo de Cultura Económica.

Burin, M., y Meler, I. (2005). Informe final de investigación: género, familia, trabajo. Recuperado de www.uces.edu.ar/departamentos/investigación

Butler, J. (2001). El género en disputa: El feminismo y la subversión de la identidad (1. ${ }^{\mathrm{a}}$ Ed.). (Trads. M. Mansour, y L. Manríquez) México: Paidós.

Butler, J. (2002). Cuerpos que importan: sobre los límites materiales y discursivos del sexo. Buenos Aires: Paidós.

Butler, J. (2006a). Deshacer el género. Barcelona, España: Paidós.

Butler, J. (2006b). ¿El fin de la diferencia sexual? En J. Butler. Deshacer el género (pp. 247-287). Barcelona: Paidós.

Camacho, K. (2006). Las confesiones de las confecciones: el sistema de la maquila de confecciones en Medellin, condiciones laborales y de vida de las mujeres trabajadoras. Medellín: Escuela Nacional Sindical, Colciencias.

Carrasco, C. (2003). La sostenibilidad de la vida humana: ¿un asunto de mujeres? En M. León (Ed.), Mujeres y trabajo: cambios impostergables (pp. 11-49). Porto Alegre, Brasil: Consejo Latinoamericano de Ciencias Sociales CLACSO; Marcha Mundial de las Mujeres; Red de Mujeres Transformando la Economía REMTE.

Castellanos, G., Grueso, D. I., y Rodríguez, M. (2009). Introducción. En Autores, Identidad, cultura y política: perspectivas conceptuales, miradas empíricas (pp. 9-33). Cali: Programa Editorial Universidad del Valle. 
Castells, M. (2000). La era de la información. Economía, Sociedad y Cultura. Vol I. La sociedad red. México: Siglo XXI.

Castells, M., y Himanen, P. (Eds.). (2014). Reconceptualizing development in the global information age. Oxford: Oxford University Press.

Correa, M. E. (2005). La feminización de la educación superior y las implicaciones en el mercado laboral y los centros de decisión política. Recuperado de www.mineducacion.gov.co/cvn/1665/articles-92159_archivo_pdf.pdf

Daza, S. (2010). Las mujeres en el SNCTI. Balance de una década en condiciones diferentes. En Indicadores de Ciencia y Tecnología Colombia 2010 (pp. 279316). Bogotá, Colombia Observatorio Colombiano de Ciencia y Tecnología.

Deleuze, G. (1987). Foucault. Barcelona, España: Paidos.

Du Gay, P. (2003). Organización de la identidad: gobierno empresarial y gestión pública. En P. Du Gay y S. Hall (Comps.), Cuestiones de identidad cultural (pp. 251-280). Buenos Aires, Argentina: Amorrourtu.

Federici, S. (2013). Revolución en punto cero. Trabajo doméstico, reproducción y luchas feministas. Traficantes de sueños Mapas. Recuperado de https://www.traficantes.net/sites/default/files/pdfs/Revolucion $\% 20$ en $\% 20$ punto $\% 20$ cero-TdS.pdf

Fernández, A. (2004). Historias de infancia. En C. García (Ed.), Hacerse mujeres, hacerse hombres, dispositivos pedagógicos de género (pp. 25-46). Bogotá, Colombia: Siglo del Hombre, Departamento de investigaciones de la Universidad Central, Casa de la mujer, Consejería Presidencial para la Equidad de la Mujer.
Fernández, M. (2016). El origen de la mujer cuidadora: apuntes para el análisis hermenéutico de los primeros testimonios. Index de Enfermería, 25(1-2), 93-97.

Foucault, M. (1972). La arqueología del saber (2. ${ }^{a}$ Ed.). (Trad. A. Garzón del Camino) México: Siglo XXI.

Foucault, M. (1991). Por qué estudiar el poder: la cuestión del sujeto. En Autor. El sujeto $y$ el poder (Trads. M. C. Gómez y J. C. Ochoa, pp. 51-103). Bogotá, Colombia: Carpe Diem.

Foucault, M. (1992a). Microfisica del poder (3. ${ }^{a}$ Ed.). (Trads. J. Varela y F. Álvarez) Madrid, España: La Piqueta.

Foucault, M. (1992b). La verdad y las formas jurídicas (3. ${ }^{\mathrm{a}} \mathrm{Ed}$.). (Trad. E. Lynch) Barcelona, España: Gedisa.

Foucault, M. (1998). Historia de la sexualidad 2. El uso de los placeres. (Trad. M. Soler) Madrid, España: Siglo XXI.

Foucault, M. (1999). La ética del cuidado de sí mismo como práctica de la libertad. En Autor, Estética, ética y hermenéutica (pp. 393-415). Buenos Aires, Argentina: Paidós.

Foucault, M. (2003). Historia de la sexualidad 1. La voluntad del saber (2. ${ }^{\mathrm{a}}$ Ed.). (Trad. U. Guiñazú). Buenos Aires, Argentina: Siglo XXI.

Foucault, M. (2005). Vigilar y castigar: nacimiento de la prisión (34. ${ }^{\mathrm{a}}$ Ed.). (Trad. A. Garzón Del Camino) México: Siglo XXI.

Foucault, M. (2008). El orden del discurso. (Trad. A. González Troyano). Barcelona, España: Fábula Tusquets Editores.

Gergen, K. J. (1997). El yo saturado. Dilemas de identidad en el mundo contemporáneo. (Trad. L. Wolfson). Barcelona, España: Paidós. 
Giddens, A. (2000). Modernidad e identidad del yo. El yo y la sociedad en la época contemporánea. (3. ${ }^{a}$ Ed.). (Trad. J. L. Gil Aristu) Barcelona, España: Ediciones Península.

Giménez, V., y Mallimaci, F. (2006). Historia de vida y métodos biográficos. En I. Vasilachis de Gialdino (Ed.), Estrategias de investigación cualitativa (pp. 175212). Barcelona, España: Gedisa.

Guirao, C. (2011). Nuevas formas de relación. Trabajo productivo y sociedad: La conciliación de la vida familiar y laboral. Prisma Social, (6), 1-27.

Goetz, J., y LeCompte, M. (1988). Etnografia $y$ diseño cualitativo en investigación educativa. Madrid, España: Morata.

González, F. (2007). Investigación cualitativa $y$ subjetividad. Los procesos de construcción de la información. México D.F.: McGraw Hill Interamericana.

Gómez García, P. (2000). Las ilusiones de la identidad. Madrid: Ediciones Cátedra.

Gutiérrez, S. (2010). De niñas a ingenieros: Transformaciones del discurso de las mujeres y relaciones de género en la Facultad de Ingeniería de la UABC en Mexicali. VIII Congreso Iberoamericano de Ciencia, Tecnología y Género.

Guzmán, V., Todaro, R., y Godoy, L. (2017). Biografías de género en contextos de cambio. Chile 1973-2010. Psykhe, 26(1), $1-13$.

Hall, S. (2003). Introducción: ¿quién necesita "identidad"? En P. Du Gay, y S. Hall, Cuestiones de identidad cultural (Trad. H. Pons; pp. 13-39). Buenos Aires, Argentina: Amorrourtu.

Harvey, D. (1998). La condición de la postmodernidad. Investigación sobre los orígenes del cambio cultural. Buenos Aires. Argentina: Amorrortu Editores.
Hirata, H., y Kergoat, D. (1998). Una nueva mirada a la división sexual del trabajo. En M. Maruani, C. Rogerat y T. Torns (Eds.), Las nuevas fronteras de la desigualdad: hombres y mujeres en el mercado del trabajo (Trad. M. Bofill, pp. 139-155). Barcelona, España: Icaria.

Kornblit, A. L. (2007). Historias y relatos de vida: una herramienta clave en metodologías cualitativas. En A. L. Kornblit (Ed.), Metodologías cualitativas en ciencias sociales. Modelos y procedimientos de análisis (pp. 15-33). Buenos Aires. Argentina: Biblos.

Lamas, M. (2003). Uso, dificultades y posibilidades de la categoría "género". En M. Lamas (Ed.), El género: la construcción cultural de la diferencia sexual (pp. 327 366). México D.F.: Universidad Nacional Autónoma de México Programa Universitario de Estudios de Género PUEG.

Lisbona, A., López, M., y Saínz, M. (2004). Mujeres ingenieras: percepciones sobre su vida profesional. Revista de Psicología General y Aplicada, 57(2), 161-180.

Lyotard, J. F. (1994). La condición postmoderna. Madrid, España: Cátedra.

Lyotard, J. F. (1995). La postmodernidad (explicada a los niños). Barcelona, España: Gedisa.

Maciel Noyola, M. D., Ruíz Martínez, A., y Cruz Cabrera, B. (2016). Doble jornada de trabajo y calidad de vida de las mujeres que laboran en la Secretaría de Administración del gobierno del Estado de Oaxaca. Un estudio desde la perspectiva de género. Mérida: 21 Encuentro Nacional sobre Desarrollo Regional en México.

Moore, H. (1991). Antropología y feminismo. Madrid, España: Cátedra, Universitat de Valencia, Instituto de la mujer. 
Molinier, P. (2011). Antes que todo, el cuidado es un trabajo. En L. Arango, y P. Molinier (Eds.), El trabajo y la ética del cuidado (pp. 45-64). Bogotá: La carreta Editores Universidad Nacional de Colombia.

Offe, C. (1984). Trabalho como categoria sociológica fundamental? En Autor, Trabalho $y$ sociedade. Problemas estruturais $e$ perspectivas para o futuro da sociedade do trabalho (pp. 13-41). Rio de Janeiro, Brasil: Edições Tempo Brasileiro.

Organización Internacional del Trabajo, Programa de Desarrollo las Naciones Unidas OIT- PNUD. (2008). Trabajo y familia hacia nuevas formas de corresponsabilidad social. Nueva York: OIT PNUD.

Otálvaro-Marín, B., Ceballos-Molano, R., Bonilla-Mejía, L. M., y Gómez, C. V. (2018). Violencias de género: un conflicto a transformar en la educación superior en Colombia. Revista Entorno, (66), 136-147.

Perdomo, I. (15 de Julio de 2009). Matemática $y$ género. Una aproximación histórica. Organización de Estados Iberoamericanos para la Educación, la Ciencia y la Cultura. Recuperado de www.oei.es/cienciayuniversidad/spip.php?article447

Pérez Tapias, J. A. (2000). ¿Identidades sin fronteras? Identidades particulares y derechos humanos universales. En P. Gómez García, Las ilusiones de la identidad (pp. 55-98). Madrid, España: Ediciones Fronesis Cátedra Universitat de Valencia.

Restrepo, E. (2009). Identidad: apuntes teóricos y metodológicos. En G. Castellanos, D. I. Grueso, y M. Rodríguez, Identidad, cultura y política: perspectivas conceptuales, miradas empíricas (pp. 61-75). Cali, Colombia: Programa Editorial Universidad del Valle.
Rodríguez, R. (1999). Foucault y la genealogía de los sexos. Barcelona, España: Anthropos

Rodríguez Pizarro, A., e Ibarra Melo, M. (2013). Estudios de género en Colombia. Una discusión preliminar. Sociedad y Economía, (24), 15-46.

Rose, N. (2003). Identidad, genealogía, historia. En P. Du Gay y S. Hall, Cuestiones de identidad cultural (pp. 214-250). Buenos Aires, Argentina: Amorrourtu.

Rubin, G. (2003). El tráfico de mujeres: nota sobre la economía política del sexo. En M. Lamas (Ed.), El género: la construcción cultural de la diferencia sexual (pp. 3596). México D.F.: Universidad Nacional Autónoma de México Programa Universitario de Estudios de género PUEG.

Scocco, M. (2018). La interseccionalidad del trabajo. Las transformaciones en el trabajo de las mujeres en Argentina. Reflexiones, 1(97), 77-84.

Scott, J. (1990). El género: una categoría útil para el análisis histórico. En J. Amelang, y M. Nash (Eds.), Historia y género: las mujeres en la Europa Moderna y Contemporánea (pp. 23-56). Valencia, España: Alfons el Magnanim.

Scott, J. (2000). La mujer trabajadora en el siglo XIX. En G. Duby y M. Perrot, Historia de las mujeres en occidente. El siglo $X I X$ (pp. 427-461). Madrid, España: Taurusminor Santillana.

Tereso Ramírez, L., y Cota Elizalde, B. D. (2017). La doble presencia de las mujeres: conexiones entre trabajo no remunerado, construcción de afectos-cuidados y trabajo remunerado. Margen, (85), 1-12. 
Torres, E. (2013). Poder, sociedad y economía en Manuel Castells. 1983-2003: Estudio sistemático de una relación. Revista crítica de ciencias sociales, 102, 43-70.

Urrea, F. (1994). La categoría de género en las ciencias sociales contemporáneas. En S. Accorsi, G. Castellanos y G. Velasco (Eds.), Discurso, género y mujer (pp. 4976). Cali, Colombia: La Manzana de la Discordia Universidad del Valle.
Valcuende del Rio, J., y Blanco López, J. (2015). Hombres y Masculinidad ¿Un cambio de modelo? Maskana, 6(1), 1-17. doi: 10.18537/mskn.06.01.01 